\title{
BUENAS PRÁCTICAS QUE DESARROLLAN LA COMPETENCIA MEDIÁTICA EN ENTORNOS SOCIOEDUCATIVOS
}

\section{GOOD PRACTICES FOR THE DEVELOPMENT OF MEDIA COMPETENCES IN SOCIOEDUCATIONAL CONTEXTS}

\author{
Dra. Rocío Cruz-Díaz ${ }^{1}$ \\ mrcrudia@upo.es \\ Dra. Rosario Ordóñez-Sierra ${ }^{2}$ \\ rordonez@us.es \\ Dra. Sara Román García ${ }^{3}$ \\ sara.roman@uca.es \\ Dr. Francisco Pavón Rabasco ${ }^{4}$ \\ francisco.pavon@uca.es \\ ${ }^{1}$ Universidad Pablo de Olavide de Sevilla. Facultad de Ciencias Sociales. Dpto. de Educación y Psico- \\ logía Social. Carretera de Utrera, Km 1 (41013) Sevilla (España). \\ ${ }^{2}$ Universidad de Sevilla. Facultad de Ciencias de la Educación. Departamento de Didáctica y Organi- \\ zación Educativa. c/ Pirotecnia s/n (Campus Ramón y Cajal) 41013, Sevilla (España). \\ ${ }^{3}$ Universidad de Cádiz. Facultad de Ciencias de la Educación. Dpto. de Didáctica de la Educación \\ Física, Plástica y Musical.Avda. República Saharaui s/n, Campus del Río San Pedro, 11519, Puerto \\ Real (Cádiz) (España).
}

El presente artículo muestra un conjunto de buenas prácticas desarrolladas en centros e instituciones educativas (Infantil, Primaria, Secundaria, Universidad, adultos y mayores), que trabajan competencias mediáticas en las provincias andaluzas. Metodológicamente, se ha realizado una observación por cada provincia andaluza, dichas experiencias nos han dado a conocer cada institución y el colectivo en el que están enmarcados, ofreciéndonos datos de relevancia sobre cada caso o "Buenas prácticas" educativas. Se procuran ejemplos diversos de educación mediática en un amplio rango de entornos de aprendizaje, poniéndose de manifiesto la diversidad de enfoques a la hora de programar prácticas de alfabetización en competencia mediática.

Palabras clave: Buenas prácticas, competencia audiovisual, competencia mediática, ciudadanía andaluza, TIC.

This paper presents a set of good practices in Educational Centers and Institutions (Nursery school, Pre-school, Primary School, Secondary School, Higher Education, Adult Education and Senior Citizen Education), that focusing on media competences and located at in the provinces of Andalusia. Methodologically, for every Andalusian province an observation was made, in such a way that the experiences show us findings about each institution, and the people involved. The observation offered us relevant data on every case or so-called "educational good practices". Different examples of media education are offered in a wide range of learning contexts, as well as a great diversity of approaches when programming literacy practices in media competences.

Key words: Good practices, audiovisual competence, media competence, Andalusian citizenship and ICT.

Píxel-Bit. Revista de Medios y Educación. No 48 Enero 2016. ISSN: 1133-8482. e-ISSN: 2171-7966. doi: http://dx.doi.org/10.12795/pixelbit.2016.i48.07 


\section{Introducción.}

En este artículo se presenta el proyecto extraído del estudio denominado $L a$ competencia audiovisual de la ciudadanía andaluza. Estrategias de Alfabetización mediática en la sociedad del ocio digital. La iniciativa parte de un grupo de investigadores de la Universidad de Huelva, con la intención de implementar en la ciudadanía andaluza el concepto de «competencia audiovisual» (audiovisual skills), diagnosticando rigurosamente su punto de partida, detectando sus necesidades y carencias y, estableciendo un amplio programa evaluativo que derivase en propuestas formativas ciudadanas centradas en los espacios de ocio y tiempo libre y en los entornos mediáticos del hogar, a través de los medios de comunicación. Para el desempeño de los objetivos propuestos se ha tomado como referentes las aportaciones de los expertos en torno al concepto de competencia audiovisual en entornos digitales (Aguaded, Ferrés, Cruz, Pérez, Sánchez \& Delgado, 2011; Aguaded \& CruzDíaz, 2014; Ferrés, 2006, 2007; Ferrés \& Pricitelli, 2012) y los indicadores de las dimensiones definidas sobre la misma en los estudios liderados por dichos expertos.

Nos cuestionamos, a menudo, sobre dónde nos encontramos y consultamos los resultados obtenidos en la literatura científica (artículos, informes, investigaciones...) más reciente sobre alfabetización en medios, competencia mediática y tecnologías de la comunicación y la información. Como investigadores nos interesa no solo el estado de la cuestión, sino indagar sobre procesos de adquisición de desempeños y respuestas de los ciudadanos de hoy, en todos los sectores y grupos poblacionales -niños, jóvenes, adultos y mayores- ante la cultura digital, cultura virtual, cultura electrónica, etc. Eco de las afirmaciones de las nuevas formas de alfabetización digital justificadas por instancias e instituciones políticas, económicas y educativas nacionales e internacionales como las recomendaciones de la Unión Europea (OECD-Agenda de París para la Educación en Medios, 2007; Parlamento Europeo, 2008; CCERecomendación de la Comisión Europea, 2009; legislación española-LOE, 2006; Ministerio de Educación-MEC, 2011), entre otras. Ello implica el desarrollo de competencias que nos permitan superar la tan proclamada brecha digital y les faciliten la posibilidad de leer, interaccionar y ser críticos con los recursos tecnológicos y las pantallas (Santibáñez, 2013).

El estudio de Costa, Cuzzocrea y Nuzzaci (2014) sobre las diferentes características del uso de Internet en un ambiente informal, realizado con una muestra de 191 sujetos, a partir de las preguntas: ¿Cómo aprovechar el enorme potencial de esta herramienta para ayudar a las personas en su aprendizaje?, ¿cuáles son las características cognitivas y sociales tanto de niños y jóvenes como de adultos y mayores que las emplean?, ¿qué habilidades se necesitan para seleccionar y gestionar la información y la comunicación?, entre otras, evidencia la necesaria reflexión sobre las posibilidades y ventajas que pueden derivarse de su uso en la educación.

Hoy en día el acceso a las Tecnologías de la Información y Comunicación (TIC) está teniendo consecuencias fundamentalmente positivas en la ciudadanía, tanto a nivel personal como familiar, profesional y social, sin embargo, la influencia de los medios de comunicación muchas veces no va acorde con el desarrollo de la alfabetización 
mediática. Las aportaciones de García, Ramírez y Rodríguez (2014), nos permiten constatar que el nivel de competencia mediática de los niños y jóvenes españoles no ha conseguido aún un nivel óptimo, por lo que es importante seguir trabajando para que el currículum escolar se ocupe de la alfabetización mediática como elemento fundamental para la formación de ciudadanos «prosumidores» que participen activamente en la sociedad con un marcado carácter crítico y analítico. Su investigación, de ámbito estatal, pretende identificar los niveles de competencia mediática, encuestando a una muestra de 2.143 estudiantes de Educación Infantil, Primaria, Secundaria y Bachillerato, mediante un cuestionario ad hoc online.

Los resultados ponen de manifiesto que una parte importante de la muestra es competente ante los medios, en un nivel aceptable, pero sin embargo, y a pesar de que pertenecen a la generación de los denominados «nativos digitales» (Prensky, 2001), otros no poseen las habilidades necesarias para ejercer como «prosumidores mediáticos». Concluyen destacando la necesidad de complementar la competencia digital establecida en el currículum escolar con la competencia mediática, como elemento clave para desarrollar una «cultura prosumidora». Para Ramírez, Renés y Sánchez (2013, p.2) la cultura digital es eminentemente participativa, «...que los ciudadanos sean capaces de desarrollar capacidades y estrategias que les permitan no solamente consumir medios, sino producirlos, crearlos, diseñarlos, ser agentes activos de los procesos de construcción de significados digitalizados, fomentando asi prosumidores inteligentes».

En la misma línea, considerando el mundo global e intercultural de hoy en día, Gutiérrez y Tyner (2012) abordan el papel que le corresponde a la educación formal tanto en la integración curricular de los medios como en la alfabetización digital necesaria, proponiendo una alfabetización para el siglo XXI: mediática, digital, multimodal, crítica y funcional. Y nos advierten del peligro de reducir la educación mediática al desarrollo de la competencia digital y la competencia digital a su dimensión más tecnológica e instrumental, centrándose en los conocimientos técnicos, en los procedimientos de uso y manejo de dispositivos y programas, olvidando las actitudes y los valores. El desarrollo eficaz de las destrezas comunicativas supone en el individuo, haber adquirido competencia en comunicación audiovisual, entendida por Ferrés como «la capacidad de un individuo para interpretar y analizar desde la reflexión crítica las imágenes y los mensajes audiovisuales y para expresarse con una mínima corrección en el ámbito comunicativo» (2007, p. 102). El autor otorga seis grandes dimensiones a la «Competencia en Comunicación Audiovisual en la era digital»: el lenguaje, la tecnología, la ideología y los valores, la producción y programación, la recepción y las audiencias, y la dimensión estética. Estas dimensiones se desglosan en categorías según el análisis y la expresión de las mismas.

\section{Instrumentos: Experiencias de «Buenas prácticas» en entornos socioeducativos.}

En este apartado se presenta brevemente el marco en el que se han desarrollado las diferentes experiencias llevadas a cabo en los 8 escenarios de las provincias andaluzas:

La Caza del Tesoro se desarrolla en el Centro de Educación Infantil y Primaria (CEIP) 
San Walabonso (Huelva). Centro ampliamente vinculado a convocatorias de Proyectos de innovación, en concreto, dentro del Proyecto de alfabetización mediática «Escuela web 2.0». La persona responsable es mujer, de 50 años con amplia experiencia y formación en alfabetización mediática. La actividad consiste en la realización por parte del alumnado de una página de trabajo en formato digital (página web), mediante un enlace que se inserta en la página web del colegio. El objetivo es ampliar conocimiento sobre un tema en concreto desde la perspectiva mediática, elaborando para ello un diseño web y aprendiendo a seleccionar información adecuada en la red.

Encargo profesional de fotografías para libro de farmacia. En dicha actividad, llevada a cabo en un Instituto de Educación Secundaria (IES) de Almería, participaron 4 alumnos de Ciclo Formativo de Grado Medio de Laboratorio de Imagen, 3 profesores de dicho Ciclo y una profesora (autora del libro y compañera del centro), de la rama sanitaria, realizadora de las fotografías necesarias para un manual de medicamentos. La autora (docente del centro) interviene activamente, informando sobre el contenido de las fotografías, en este caso sobre los medicamentos, sus recetas, las simbologías, etc. Los objetivos han sido colocar al alumnado ante una situación real de trabajo, enfrentándolos a la resolución de lo planteado según las exigencias del cliente, desarrollando su capacidad de autoformación, documentación, análisis y resolución autónoma, manteniendo un nivel de calidad profesional.

Radio escolar «El Trocadero». Ésta actividad se desarrolla en el CEIP «El Trocadero» de la localidad de Puerto Real (Cádiz) y se enmarca en un Proyecto educativo puesto en marcha hace ya 10 años. La observación consiste en la grabación y emisión desde el colegio público del programa de radio preparado por el alumnado de Infantil de 3 años, grupo C. Era el último programa de radio del año académico, una vez en el recinto de la radio escolar, con el saludo de bienvenida, el profesor responsable da instrucciones: por grupos de 5 se acercan sucesivamente a la gran mesa para intervenir. Como sesión añadida, y por ser el penúltimo día de clase antes de finalizar el curso escolar, se entrevista a dos alumnos, chico y chica, de $6^{\circ}$ curso, que dicen adiós al centro. Mediante la realización periódica de esta actividad, el alumnado se siente protagonista en un medio de comunicación y aprenden a valorarlo.

El taller «Apaga la tele y enciende un libro», tiene lugar en el CEIP Genil (La Montiela) de Córdoba. Coincidiendo con el comienzo del curso escolar se desarrolla la experiencia, con un grupo de $3^{\circ}$ curso de Infantil, consistente en el visionado del corto de Disney sobre la fábula «Los tres cerditos», para trabajar el tema de los valores transmitidos a través de las fábulas tradicionales y sus películas, que llevan elaborando desde $1^{\circ}$ curso de Infantil. El objetivo inicial es desarrollar en el alumnado los valores de responsabilidad, tolerancia, generosidad, cooperación y respeto mutuo, vinculados a la competencia mediática si tenemos en cuenta que, los medios transmiten valores y creencias y es, precisamente en esta etapa, cuando los niños/as empiezan a socializarse en su grupo de iguales y a dar sus primeros pasos en la formación de su personalidad.

Taller de edición de fotos en el Centro Guadalinfo en la provincia de Granada, en el marco del proyecto «Infancia 2.0». El taller se 
imparte los meses de verano y participan 11 niños/as con edades entre los 8 y los 12 años. La docente tiene amplia experiencia en el tema. El objetivo principal del taller es que los niños/ as aprendan los procedimientos técnicos vinculados al tratamiento fotográfico de la imagen digital: buscar, guardar y clasificar fotografías en el ordenador, editarlas posteriormente en un software on line específico para la infancia.

Taller de alfabetización mediática «Conocer los medios de comunicación» para Altas Capacidades Intelectuales. MENTORAC-UMA. La actividad se desarrolla en la Universidad de Málaga y consiste en un taller sobre medios de comunicación desarrollado en el marco del Programa de Mentorías Universitarias para alumnado con Altas Capacidades Intelectuales en la Universidad de Málaga. Los objetivos del taller fueron distinguir las posibilidades entre los diferentes medios de comunicación y algunas prácticas comunicativas, conocer las potencialidades de los medios de comunicación actuales más importantes de cara a la elección de estudios relacionados con este ámbito y obtener conocimientos mínimos para analizar críticamente los mensajes de los medios de comunicación. Los asistentes al taller son estudiantes de periodismo y 3 alumnas de AACC. Los alumnos/as de periodismo se reúnen por grupos y debaten sobre 10 preguntas clave sobre el tema, mientras las 3 alumnas de AACC responden a un cuestionario sobre su uso y conocimiento de la prensa, la radio, la televisión e Internet, finalizando con un debate.

Taller sobre cómo crear y mantener cuentas de correo: El caso de Gmail. La actividad se desarrolla en la Asociación de exalumnos/as del Aula abierta de Mayores de Castilleja de la Cuesta (Sevilla) y está enmarcada en el Programa anual de actividades patrocinado por el Programa Universitario «Aula Abierta de Mayores» de la Universidad Pablo de Olvide y la Diputación Provincial de Sevilla. El responsable de la actividad tiene experiencia en alfabetización y los objetivos de la sesión son que los mayores conozcan los recursos de comunicación que ofrece Internet; aprendan a crear y a mantener un correo electrónico y; desarrollen destrezas comunicativas de relación interpersonal. Las edades de los asistentes oscilan entre los 59 y $\operatorname{los} 72$ años.

La actividad sobre las regiones francesas se realiza en el IES AZ-ZAIT de Jaén, centro TIC, aunque no vinculado a Proyectos de Innovación o Alfabetización. La actividad consistente en recopilar información sobre las diferentes regiones/ departamentos de Francia elaborando una presentación multimedia sobre la región asignada. Las indicaciones dadas al alumnado para la elaboración del trabajo son las siguientes: La presentación debe organizarse pensando en que debería servir a un turista que fuese a visitar la región por primera vez y deseara realizar allí una estancia de 4 días. En dicha presentación deben situar en el espacio a personas que nunca han visitado esos lugares, así como mostrar los aspectos más importantes de la región: geografía, clima, gastronomía, ciudades relevantes... Además deben seleccionar dos ciudades y destacar lo más importante de ellas desde el punto de vista turístico, finalizado el trabajo, los diferentes grupos realizarán su exposición. 
3. Metodología del estudio en su interés por «Indagar perfiles de experiencias de 'Buenas prácticas' en alfabetización audiovisual y contenidos de ocio digital».

El trabajo desarrollado mediante la recogida de experiencias de buenas prácticas, nos permite validar la metodología de observación, así como poner a disposición de la comunidad científica unos instrumentos de recogida de datos que podrían utilizarse en otros contextos de educación formal y no formal. Las experiencias aquí recogidas no pretenden ser representativas, sólo nos indican el nivel de competencia mediática en cada uno de los casos abordados en la investigación.

Siguiendo a García, Ramírez y Rodríguez (2014) el establecimiento de grados de competencia en cada caso, nos ayudará a determinar cuáles son las dimensiones en las que se aprecian más carencias y por tanto, se requiere una mayor intervención para lograr los objetivos de la alfabetización mediática.

\subsection{Objetivos del estudio.}

Son objetivos del Proyecto P10-SEJ-5823, en el que se enmarca este estudio realizado mediante la técnica de observación sobre «Buenas prácticas» en las 8 provincias andaluzas, los siguientes:

Detectar las necesidades y carencias de la población andaluza seleccionada en relación con los niveles de competencia en comunicación: tecnología, lectura crítica y producción audiovisual.

Redefinir los indicadores de referencia para medir el grado de competencia en comunicación en sectores poblacionales diferenciados de todas las provincias de Andalucía.
Diagnosticar los niveles y grado de competencia audiovisual de las muestras seleccionadas. Indagar perfiles de experiencias de «Buenas prácticas»en alfabetización audiovisual y contenidos de ocio digital.

\subsection{Técnica de recogida de información: la observación.}

En la parte del estudio que se presenta aquí, la metodología utilizada para el trabajo de campo ha sido la observación directa de las prácticas educativas; los objetivos como definíamos anteriormente, son los propios de investigaciones de tipo descriptivo, analizar características, propiedades o relaciones entre grupos, eventos o fenómenos sometidos a estudio, y aumentar el conocimiento sobre problemas particulares o proporcionar datos para estudios futuros en profundidad (Sabirón, 2006).

La observación, como técnica ha sido desde siempre una de las fuentes del conocimiento humano, pero es muy reciente su aplicación sistemática al servicio de las situaciones educativas (Fernández Loya, 2010). La importancia atribuida se debe al gran abanico de posibilidades que ésta tiene dentro del ámbito educativo. Al utilizar la observación como método, se han seguido todas las fases del proceso: delimitación del problema, recogida y registro de los datos, análisis de los mismos e interpretación de los resultados.

Con respecto a la muestra, se ha realizado una observación por cada provincia; seleccionando «experiencias educativas» significativas en las que se trabajen aspectos vinculados a la competencia mediática. Dichas experiencias nos han dado a conocer cada centro/institución y el colectivo en el que 
están enmarcados (Infantil, Primaria, Secundaria, Universidad, Adultos y Mayores), ofreciéndonos datos de relevancia sobre la realización de «Buenas prácticas» concretas.

Para el desarrollo de las experiencias presentadas en este documento el equipo investigador ha contactado directamente con estos centros, conociendo el interés y buena disposición de los profesionales para trabajar la competencia mediática en comunicación audiovisual.

El instrumento consta de los siguientes apartados:

1. Datos de identificación.

2. Descripción de la actividad detallando sus objetivos, competencias, contenidos, descripción, recursos, temporalización, evaluación. Junto a un apartado específico destacando las competencias mediáticas más afines.

3. Observación especifica del tiempo de inicio y desarrollo de la actividad.

4. Presentación de la tarea y papel del responsable (Véase Tabla $\mathrm{n}^{\circ} 1$ ).

5. Descripción del ambiente (Véase Tabla $\mathrm{n}^{\mathrm{o}} 2$ ).

Las variables resultantes del análisis de las observaciones han sido obtenidas de la categorización de las competencias mediáticas descritas en el estudio de Ferrés (2007) -el lenguaje, la tecnología, la ideología y los valores, la producción y programación, la recepción y las audiencias, y la dimensión estética-.

\section{Resultados de estudio de los casos de «Buenas prácticas» en competencia mediática.}

Para el presente trabajo, y aunque las experiencias llevadas a cabo en cada una de las provincias han sido muy diferentes, se ha utilizado una plantilla con indicadores comunes para los 8 escenarios observados, al mismo tiempo que cada responsable de la sesión observada debía completar unas determinadas tablas (véanse Tablas 1 y 2).

De las sesiones observadas 4 se ponen en práctica en Centros de Educación Infantil y Primaria, 2 observaciones en un Instituto de Educación Secundaria y uno de Ciclo Formativo de Grado Medio; las dos restantes se llevan a cabo en ambientes universitarios: Programa de Mentoría Universitaria y Aula Abierta de Mayores. Respecto a los profesionales que dirigen las experiencias (4 mujeres y 4 hombres), todos ellos tienen amplia experiencia docente, pero 6 de ellos no tienen formación específica en competencia mediática, contrastando con los otros 2 que han realizado gran cantidad de cursos relacionados con esta materia y cuyos Centros además están vinculados a Proyectos de Innovación y alfabetización mediática (Huelva y Granada).

Sobre los datos de la actividad, se dan a conocer el nombre, objetivos, competencias, contenidos, recursos, la descripción de la actividad, criterios de evaluación y, por último, las competencias mediáticas que se desarrollan en las mismas.

Atendiendo a los objetivos, podemos reseñar que encontramos una gran variedad en la explicitación de los mismos, llegando incluso a no repetirse en las diferentes actividades. Entre los desarrollados en las ocho actividades destacamos:

La necesidad de «ampliar conocimientos sobre el tema a través de la información almacenada en la red» (Huelva); del mismo modo, el caso de Almería pretende «desarrollar la capacidad de hacer trabajos profesionales mediante la autoformación, 
documentación, análisis y resolución autónoma de problemas»; Cádiz se centra en «desarrollar destrezas comunicativas, tanto receptivas como productivas, con el fin de realizar intercambios de información dentro y fuera del aula». Al tiempo que Córdoba se plantea «describir las creencias que tienen los niños en cuanto a los valores que transmiten los cuentos tradicionales»y Granada, considera de especial importancia «fomentar la capacidad crítica, comprendiendo los procesos de producción digital». Málaga, se concentra en «distinguir las posibilidades entre los diferentes medios de comunicación y algunas prácticas comunicativas», junto con Sevilla en dar a «conocer los recursos de comunicación que ofrece Internet». Por último, el proyecto implantado en Jaén se concentra en «desplegar la capacidad de comunicarse oralmente y por escrito de forma eficaz en situaciones habituales de comunicación a través de tareas específicas».

Atendiendo a las competencias mediáticas que se pretenden alcanzar a través de las distintas actividades, debemos mencionar que encontramos una amplia diversidad de ellas. Comenzando por Huelva, centrada en las Dimensiones Tecnológica, la Producción y programación, la Ideológica y la Estética, entre ellas: «búsqueda de imágenes e información web» (subirlas y dimensionarlas); «creación de tablas» (centrarlas, crear porcentajes adecuados en un $90 \%$ del alumnado); «realización de enlaces (centrarlas y posicionarlas en un texto)»y «guardado de la información en una carpeta específica dentro del apartado marcadores»; «agradecimientos a las páginas web su aportación en cuanto información, imágenes y documentación proporcionada». Almería dedica su atención a las mismas Dimensión del Lenguaje, Tecnología, Ideología y valores, Producción y programación, Estética: «generar imágenes descriptivas sin renunciar a la estética»; «amplificar las capacidades de comunicación del alumnado»; «autoformación y documentación en la fase de preproducción»; «catalogación y ordenación» y «uso de nuevas aplicaciones». En el proyecto de Cádiz encontramos todas las dimensiones mencionadas (Lenguaje, Tecnología, Ideología y valores, Producción y programación) junto a la Recepción y las audiencias: «elaborar información propia» que llevarán al programa de radio; «organizar la información de forma coherente» destacando los aspectos más relevantes; «utilizar el recurso radio en la exposición del trabajo asignado»; «ser originales en la elaboración y una buena presentación de lo preparado». Córdoba tan sólo destaca que es importante «desarrollar valores de responsabilidad, tolerancia, generosidad, cooperación y respeto mutuo»Dimensiones mediáticas de Ideología y valores. En cambio Granada, hace alusión a un mayor número de competencias: Se centra más en las Dimensiones de Comunicación; Producción y Audiencias: Dimensiones éticas y estéticas: las imágenes una herramienta básica en la comunicación digital, búsqueda de imágenes); «administración de archivos y tratamiento de imagen»; «producción y programación»; «tratamiento del lenguaje e imagen en cuanto aspectos formales». De forma paralela, se impulsa la creatividad (decisiones en el tratamiento de la imagen y selección previa de la fotografía, temática etc.), aprendizaje autónomo (el tratamiento de la fotografía es abierto), el sentido estético y la capacidad crítica; dimensiones de la competencia mediática y; Competente en el 
conocimiento e interacción junto al interés por la «cultura y el arte»; y el aprendizaje personal «aprender a aprender»: Málaga, ciñe sus competencias a «distinguir las posibilidades entre los diferentes medios de comunicación y algunas prácticas comunicativas»; «dar a conocer las potencialidades de los medios de comunicación actuales de cara a decidir sobre la elección de estudios relacionados con este ámbito» y «obtener conocimientos mínimos para analizar críticamente los mensajes de los medios de comunicación». El proyecto de Sevilla, enmarca sus competencias en las Dimensiones Tecnológica y de Lenguaje con el «acceso y búsqueda de información»; «análisis de los distintos códigos lingüísticos que aparecen en la red»; «utilización de diferentes herramientas tecnológicas»; «diseñar y personalizar el correo electrónico» $\mathrm{y}$ «fomentar la comunicación mediante el uso de esta herramienta». Jaén a lo largo de la sesión desarrolla competencias mediáticas ligadas a las Dimensiones de Lenguaje y Tecnológicas, fundamentalmente, interesándose por un lado en: «elaborar información propia a partir de la búsqueda de información a través de Internet», «extraer y sintetizar la información más relevante sobre el tema asignado»; «organizar la información de forma coherente, destacando los aspectos más relevantes»y, por otro en: «utilizar recursos multimedia en la exposición del trabajo asignado»y «ser originales en la elaboración y presentación de la información recogida a través de la red».

Atendiendo a los contenidos, como es de esperar están relacionados con las actividades desarrolladas y, por tanto, volvemos a encontrar una gran diversidad y diferencia en el planteamiento de los mismos. Tales como: «Descubrimiento de América»
(Huelva); contenidos «Fotográficos y transversales» (Almería), aunque entre los segundos los detalla pormenorizadamente dentro de la maquetación, documentación y Farmacia; Cádiz, recoge contenidos que abarcan la «Comprensión, interacción y memorización»; «producción de mensajes orales»; «utilización de estrategias que potencien la fluidez y eficacia en la comunicación»; «simulaciones»; «aceptación de los errores propios»y; encontramos que Córdoba se centra en la «comprensión de valores»; «diferenciación de los roles que asumen los personajes y su extrapolación a la vida diaria»y «vinculación de conceptos visionados en el cuento con la vida cotidiana». Los lenguajes multimedia y verbal se articulan en esta actividad, mediante el visionado de la película y el debate que se establece a continuación. En cambio, Granada utiliza la «búsqueda, archivo y clasificación de imágenes» $\mathrm{y}$ «edición digital con software específico para la edad del alumnado»; Málaga se plantea entre sus contenidos grandes interrogantes «¿cómo se financia un medio de comunicación?»; «¿cómo puede influir el anunciante en el contenido de un medio?»; « ¿qué es el product placement?»; «informativos»; «prensa online Vs prensa papel»; «¿qué debe saber un espectador de televisión ante la propaganda mediática de partidos?»; «estructura de la prensa de tirada nacional»; «entramado empresarial de las grandes cadenas de televisión» $\mathrm{y}$, «¿qué es la alfabetización mediática?». De otro lado, Sevilla concentra sus contenidos en «los medios de comunicación social y las TIC»; «los recursos y herramientas de comunicación»; «creación, diseño y mantenimiento del correo electrónico»; «introducción al Gmail», etc.; Y, por último, Jaén destaca la «comprensión global de los 
mensajes más relevantes de las distintas fuentes presentadas»; «interacción y memorización»; «producción de mensajes orales»; «utilización de estrategias que potencien la fluidez y eficacia en la comunicación»; «representación de papeles en situaciones simuladas trabajadas previamente»; «desarrollo de habilidades comunicativas; perfeccionamento de la expresión escrita, organizando las frases o párrafos proporcionados, desarrollándolos y añadiendo información de manera personalizada»; «comprensión global de mensajes escritos»y «elaboración de productos personales y creativos por medio de proyectos personales que permitan una expresión personal».

Con respecto a los recursos utilizados, mayoritariamente emplean ordenadores, proyectores y la pizarra digital; otros, además mencionan el vídeo, televisión, cámaras, libros, software, equipos de audio y radio escolar.

Sobre la evaluación, cuatro observaciones presentan los criterios para evaluar la actividad, tres realizan una valoración muy positiva del desarrollo de las actividades: Huelva valora positivamente la participación e implicación del alumnado, el nivel de aprendizaje cooperativo que se forja en el aula, el aprendizaje generado en el proceso de elaboración, la entrega en plazo y la presentación final del trabajo. Respecto a la evaluación de la actividad en Almería señalar que está implícita en el propio desarrollo de la misma y en la consecución de un buen producto final. La evaluación final del alumnado la hace el cliente al aceptar o no las fotografías, consideramos que la práctica ha sido de gran utilidad pedagógica; finalizadas las intervenciones, de la actividad realizada en Cádiz, el docente comenta los aspectos positivos de la sesión y les desea buen verano. Para Granada la totalidad de los alumnos/as consiguen los objetivos al finalizar la sesión, centrándose en la administración de archivos y tratamiento de la imagen, edición de fotografía y de lenguaje; en Sevilla la sesión es calificada como muy interesante, dinámica y participativa. Las impresiones que verbaliza el alumnado son de haber aprendido algo útil, algo que les puede servir en su vida cotidiana. En repetidas ocasiones se menciona durante la sesión «el miedo» a los ordenadores que durante años les ha retraído en su utilización y; Málaga no presenta ninguna aportación.

En cuanto al tiempo dedicado al desarrollo de la actividad en su inicio. En el desarrollo de la actividad del centro ubicado en Huelva emplean 45". La sesión se inicia instando al alumnado a pensar en un tema de investigación. Por votación la temática elegida es el descubrimiento de América. Los estudiantes crean una carpeta para dicho trabajo, con el asesoramiento de la profesora (búsqueda de imágenes y almacenaje) y desarrollan una página web siguiendo la estructura: introducción, preguntas sobre el tema, recursos, reflexión y aportación personal, conclusión y créditos. En cambio, el tiempo empleado en el proyecto de Almería es muy amplio, ya que se destinan 3 meses, 96h aproximadamente, distribuidas en $8 \mathrm{~h}$ semanales ( 2 tardes en semana) y en ella se sigue la metodología de aprendizaje por servicio. Han trabajado por equipos, y a la vez reciben clases dirigidas por los docentes. El desarrollo de la actividad ha requerido puntualmente el desplazamiento del alumnado a centros hospitalarios y a farmacias para la realización de algunas fotografías: Cádiz usa en el desarrollo de su actividad 120", en el recinto de la radio escolar, el profesor 
responsable da instrucciones y comienza la sesión. El profesor-director y las profesoras ayudan a los niños/as de 3 años a sentarse en los taburetes móviles, a ponerse los cascos y controlan la altura de los micrófonos. Comienza la sesión y la grabación se pone en marcha. El profesor es experto, sabe captar y mantener la atención de los pequeños, su voz es pausada; de forma natural va preguntando a cada uno su nombre y ellos responden emocionados sobre temas cercanos a los niños. Cada grupo termina su intervención de, aproximadamente 10", con una canción o una poesía, dirigidos por su profesora. En cambio, Córdoba y Sevilla sólo dedican 10", pero el desarrollo de la misma es al menos de una hora. En el primer caso, para la realización de una asamblea para explicar objetivos y después en un pequeño debate deberán explicar las diferencias, semejanzas entre ambos formatos y señalar qué les gustó más de cada uno y qué menos. La actividad es grupal y el aprendizaje cooperativo, con implicación de las TIC. Y, en el segundo caso, el docente comienza presentándose e invitando a explicar los conocimientos y/o vivencias que tiene el alumnado presente en relación a los ordenadores y a Internet. En cambio, Granada desarrolla la actividad durante una hora, hay un inicio grupal y sincronizado, a pesar de que han ido llegando progresivamente. Posteriormente hay un desarrollo similar de la segunda sesión, sin interrupciones, y con un número de alumnos/ as mayor. Málaga emplea un tiempo similar: $1 \mathrm{~h}$ y 15 ", en el que los asistentes al taller se presentan y dan a conocer sus inquietudes y dudas acerca del funcionamiento de los medios de comunicación. Los alumnos de periodismo elaboran su discurso teóricopráctico y las alumnas de AACC responden a un cuestionario sobre su uso y conocimiento de la prensa, la radio, la televisión e Internet, finalizando con una exposición oral a las explicaciones y el debate con los alumnos de AACC. Por último, Jaén dispone de 45", una vez comenzada la clase, la profesora indica que se van a llevar a cabo las exposiciones de las presentaciones multimedia elaboradas por los diferentes grupos. Se colocan junto a la mesa del profesor para la exposición. Se van relatando las imágenes y el texto que va apareciendo en la presentación; los estudiantes llevan un guión de la presentación que les sirve de apoyo en la exposición de la misma. Los datos de la observadora indican que el alumnado se implica más en la realización del material multimedia.

Como podemos comprobar en la Tabla 1, y mediante un análisis porcentual, evitando asignaciones por provincias o buenas prácticas encontramos que, en la Presentación de la tarea cuando se desarrolla la actividad, los observadores aportan datos enmarcados dentro de diferentes categorías. La primera, determina el sistema de control que utiliza quien monta la actividad, los datos reflejan que en cinco actividades $(62.5 \%)$ el sistema de control es autónomo; el $37.5 \%$ lo considera dependiente y sólo el $12.5 \%$ lo enmarca dentro de la categoría «andamiaje».

Con respecto a la interacción en la presentación de la tarea un $62.5 \%$ la realiza en grupo y el $37.5 \%$ restantes de forma dual, del mismo modo, otro $62.5 \%$ utiliza en dicha exposición el uso de TIC Atendiendo a las formas de aprendizaje, predomina la cooperativa con un $62.5 \%$ de la muestra, seguida de la colaborativa que es desarrollada por un $50 \%$ y sólo un $25 \%$ se decanta por el autoaprendizaje.

Sobre el tipo de lenguaje más empleado en la presentación de la actividad, como era de 


\begin{tabular}{|c|c|c|c|c|c|c|}
\hline & $L A A C T I V I D A D$ & \multicolumn{5}{|c|}{ EL/ARESPONSABLE } \\
\hline \multicolumn{2}{|c|}{ PRESENTACION DE LA TAREA } & \multicolumn{5}{|c|}{ EL PAPEL DEL RESPONSABLE } \\
\hline \multirow{3}{*}{$\begin{array}{l}\text { Control de la } \\
\text { Actividad }\end{array}$} & Autónomo & & & & & \\
\hline & Dependiente & & 12 & 3 & 45 & \\
\hline & Andamiaje & Activo & & & & Pasivo \\
\hline \multirow{4}{*}{ Interacción } & Dual & Facilitador & & & & Bloqueador \\
\hline & Grupal & Motiva & & & & Desmotiva \\
\hline & Con $T I C$ & Feedback & & & & Feedback \\
\hline & Con Grupo Virtual & Positivo & & & & Negativo \\
\hline \multirow{3}{*}{$\begin{array}{l}\text { Formas de } \\
\text { Aprendizaje }\end{array}$} & Autoaprendizaje & Conciliador & & & & Impositivo \\
\hline & Colaborativa & Receptivo & & & & Defensivo \\
\hline & Cooperativa & Organizado & & & & Desorganizado \\
\hline \multirow{3}{*}{ Lenguajes } & Verbal & Sistemático & & & & Asistemático \\
\hline & Hipermedia & Dinamizador & & & & No estimulador \\
\hline & Multimedia & Seguimiento & & & & No seguimiento \\
\hline \multicolumn{2}{|c|}{ El profesor explica de manera clara el objetivo de la actividad } & onentado a & & & & \\
\hline \multicolumn{2}{|c|}{$\begin{array}{l}\text { La actividad propuesta suscita orientaciones por parte del } \\
\text { alumnado }\end{array}$} & logros & & & & \\
\hline \multicolumn{2}{|c|}{$\begin{array}{l}\text { El profesor responsabiliza al alumnado de sus } \\
\text { Aprendizajes }\end{array}$} & Otros: & & & & \\
\hline \multicolumn{7}{|c|}{ Valora la Actividad: Sencilla 12345 Compleja } \\
\hline \multicolumn{7}{|c|}{$\begin{array}{c}\text { Organización del espacio } \\
\text { (agrupamientos de los alumnos/as en el aula, disposición espacial, en qué medida cambia la estructura organizativa } \\
\text { cuando se propone la actividad) }\end{array}$} \\
\hline
\end{tabular}

Tabla 1. Presentación de la tarea y papel del responsable. Fuente Elaboración propia.

esperar, el verbal es utilizado por el $87.5 \%$ de los grupos, si es interesante reseñar que además otro $50 \%$ utiliza además hipermedia y multimedia, respectivamente. El 100\% de la muestra observada, aclara que el profesor explica de manera clara el objetivo de la actividad, sólo 1 caso (12.5\%), responde acto seguido, que la actividad que ha sido propuesta no suscita orientaciones por parte del alumnado. El 37.5\%, de los profesores responsabiliza al alumnado de sus aprendizajes. Por último, cuando se le asigna una valoración a la actividad del 1 al 5, en el que 1 es sencilla y 5 compleja; encontramos que el $50 \%$ lo encuadra en un nivel intermedio con la valoración 3 , un $37.5 \%$ estima que es algo compleja ya que lo encuadra en la puntuación $n^{\circ} 4$, sólo un $12.5 \%$ considera que es algo sencilla.

Sobre el Papel del Responsable, se ha facilitado a los observadores una serie de características que van del 1 con valor positivo hasta el 5 con valor negativo. Por ejemplo, la cualidad más elegida ha sido la de responsable que motiva al grupo, el 100\% de los observadores lo ha ubicado dentro del valor positivo 1. La siguiente más elegida ha sido la de facilitador, por un $87.5 \%$ de los observadores que los ha enmarcado dentro del valor 1 , sólo el $12.5 \%$ restante elige el valor 2; dato que nos aclara que nadie ha sido encuadrado en el valor contrario y negativo denominado bloqueador. Las cualidades dinamizador y conciliador, han sido elegidas respectivamente por un $75 \%$, otro $62.5 \%$ considera que desarrollan un feedback positivo. Igualmente, otro $75 \%$, enmarca a los responsables en el valor 2, que sigue poseyendo bastantes connotaciones positivas dentro de las cualidades «receptivo, organizado, sistemático y 


\begin{tabular}{|r|l|l|l|l|l|l|}
\hline \multicolumn{7}{|c|}{ EL AMBIENTE } \\
\hline & 1 & 2 & 3 & 4 & 5 & \\
\hline Cooperativo & & & & & & Individual \\
\hline Distendido & & & & & & Tenso \\
\hline Organizado & & & & & Desorganizado \\
\hline Respeto de Normas & & & & & & Confusión/Caos \\
\hline Concentración & & & & & & Distracción \\
\hline Receptivo & & & & & & Defensivo \\
\hline Organizado & & & & & & Desorganizado \\
\hline Estimulante & & & & & & No estimulante \\
\hline
\end{tabular}

Tabla 2. Ambiente creado en el desarrollo de la actividad. Fuente: Elaboración propia.

realización de un buen seguimiento orientado a $\operatorname{los} \log r o s »$.

En relación a las características asignadas al ambiente en el que se desenvuelve la actividad se utiliza, una vez más, una tabla con 8 características que van del 1 al 5 . El más reseñado dentro del valor 1 , ha sido «receptivo» por un $62,5 \%$ de los casos, seguido de organizado y ambiente en el que se respetan las normas con un $50 \%$ en sendos casos. En el valor 2, encontramos con otro $62.5 \%$ la elección de las cualidades «cooperativo y distendido». En el valor 3, con un $37.5 \%$, se ha señalado que dichos ambientes se podían considerar poco organizados o respetuosos con las normas.

Consideramos importante, aclarar que ningún observador ha encuadrado a ninguno de los ambientes observados dentro de los valores 1 y 2 (véase Tabla 2). Cuando se interpeló sobre el tiempo empleado en el cierre de la actividad y que los observadores pudieran aportar las apreciaciones que consideraran pertinente, encontramos que, para el cierre de la actividad, en Huelva se emplean 10" recordando cómo deben entregarse las tareas y se motiva al alumnado recordando lo que han aprendido. El ambiente observado en aula es de trabajo cooperativo, caracterizado por el respeto de las normas, la concentración en la tarea propuesta, un ambiente distendido a la vez que organizado $\mathrm{y}$, un alumnado estimulado y receptivo; Almería, cierra cuando el cliente da el visto bueno a las fotografías. Las fotografías se han repetido varias veces, durante ese proceso han ido trabajando diferentes aspectos para la mejora de la misma, ya que el docente dialogaba sobre cada uno de los trabajos, hasta quedar satisfechos el equipo antes de presentárselo al cliente. La experiencia profesional del docente es extensa, conoce la importancia de saber relacionarse y presentarse a los clientes y así lo trasmite al alumnado, pidiéndoles que presenten sus trabajos fotográficos al cliente; Genera un clima de confianza, basando sus intervenciones y valoraciones hacia la mejora del producto y la dialéctica. El alumnado justifica y defiende su criterio, y acepta, por el resultado si les convence, las sugerencias del docente.

Cádiz emplea en el cierre de la actividad diez minutos. Una vez finalizadas las intervenciones de los diferentes grupos, el profesor comenta los aspectos positivos; 
Córdoba dedica igualmente 10" y el responsable cierra la sesión con un debate. Entre las observaciones incidimos en que el aula está organizada, la dinámica del aula es tranquila, el ambiente distendido y cálido, salvo en momentos puntuales que se muestran más alterados. La sesión se inicia en el tapiz para la asamblea, donde la docente explica que van a ver con imágenes el libro que han leído en clase «Los tres cerditos». Deben permanecer muy atentos para encontrar diferencias entre el cuento que leyeron y el vídeo que van a ver. Tras el visionado, se establece un pequeño debate en el que los niños/as explican las diferencias y semejanzas que han encontrado entre ambos formatos y señalan lo que más y lo que menos les gusta de cada uno de ellos; Granada plantea un cierre abierto. Todas las actividades que se realizan están enmarcadas en líneas estratégicas del centro: emprendedores, inclusión, Guadalinfancia, etc. Se trata del horario extraordinario de verano, con atención a niños durante la mañana. No obstante, el nivel de atención y concentración es alto. La docente actúa como dinamizadora y presta atención a la diversidad al haber diferentes ritmos de aprendizaje (aprendizaje cooperativo), centralizado en las indicaciones de la docente y en la atención personalizada. La actividad se basa en el aprendizaje técnico, sin vínculos específicos a lo relacionado con el criterio estético o el uso social de la fotografía. Sin embargo, la faceta de aprendizaje autónomo y la libertad creativa sí impulsan claramente la iniciativa del alumnado y las destrezas para la resolución de problemas; Sevilla, por su parte, dedica 5" al cierre de la actividad, en general la sesión ha sido muy interesante, dinámica y participativa. Las impresiones que verbaliza el alumnado son de haber aprendido algo útil, algo que les puede servir. En repetidas ocasiones se ha mencionado «el miedo»a los ordenadores que durante años les ha retraído; ahora se sienten especialmente satisfechos del uso cada vez más frecuente que hacen de ellos y de los móviles de última generación. Y, Jaén emplea 10". Una vez finalizadas las exposiciones de los diferentes grupos, la profesora comenta tanto los aspectos positivos como negativos de cada una de ellas. En relación a los contenidos, señala los puntos fuertes y débiles (información más importante recogida, estructuración de la presentación, relevancia de las imágenes que acompañan a los elementos fundamentales del trabajo, aspectos que no presentan ningún tipo de interés dentro del trabajo presentado, aspectos que deberían haberse incluido dentro de cada tema y no han aparecido).

\section{Conclusiones y Discusión del estudio.}

En los estudios de casos en «Buenas prácticas» observados podemos concluir que en la totalidad de las experiencias encontramos rasgos coincidentes con los criterios de Metodología participativa en ambientes que generan un clima favorable para el aprendizaje autónomo; Tiempos de apertura y cierre de la actividad; Logro de los objetivos en un alto porcentaje; Profesionalidad de los responsables de las actividades, Formación (Rodríguez-Gallego, 2002) y Evaluaciones positivas con respecto al logro de adquisición y desarrollo de las competencias mediáticas objeto de estudio.

Se han desarrollado competencias estrechamente ligadas a las dimensiones Tecnológicas y de Lenguaje, independientemente de los colectivos niños, jóvenes o mayores- con los que se 
haya trabajado, siendo determinante el creciente interés por los aspectos centrados en las dimensiones de Ideología y Valores, en los aspectos que generen competencias mediáticas para la Ética y la Estética, y en las dimensiones de Comunicación. Finalmente, mencionar que las menos trabajadas en los estudios presentados han sido las dimensiones cercanas a las competencias mediáticas en Producción y Audiencias.

Por otro lado, destacar que la «riqueza y valor» del estudio cualitativo realizado se ha fundamentado en la elección de la observación como instrumento de las ciencias sociales para permitirnos en todo momento «respetar la naturaleza» de cada «Buena práctica».

Para finalizar destacar el carácter innovador del estudio de casos mediante observación de «Buenas prácticas» educativas para la adquisición de competencia mediática en todos los colectivos, infantil, secundaria, universidad / niños, jóvenes, adultos y mayores y ámbitos socioeducativos, siendo sensible al efecto y posibilidades que las Tecnologías ofrecen a la educación y cultura (Rodríguez-Gallego \& García-Jiménez, 2011).

La literatura científica afirma que la eficacia de los procesos de enseñanza-aprendizaje está condicionada, en buena parte, por la eficacia de los sistemas de seguimiento y evaluación que éstos incorporen. Citando las reflexiones del profesor Ferrés i Prats en su artículo La competencia en comunicación audiovisual: dimensiones e indicadores, el abandono en que se encuentra la educación en comunicación audiovisual queda manifiesto, entre otros por la carencia que durante décadas ha padecido el sistema educativo, en particular y la sociedad, en general, de una adecuada definición, precisa y consensuada, de todo aquello que comporta mostrar nuevas destrezas y competencias en lo audiovisual y comunicativo. La competencia mediática que podemos adquirir en nuestro proceso de formación, ha sido caracterizada como una capacidad «semiótica» general de la persona para integrar, comprender y producir mensajes (Aguaded \& Cruz-Díaz, 2014), añadiríamos en entornos digitales y audiovisuales. Para éstos $\mathrm{y}$, considerando los vertiginosos avances tecnológicos que sufre la sociedad actual, la competencia mediática e informática debe asumirse no sólo como la capacidad de usar instrumentos, sino como la capacidad de aprender y desaprender el uso y producción de los medios y canales basados en las tecnologías de comunicación, información y electrónica. Deben ser transferibles y, por tanto, aplicables en determinados contextos $\mathrm{y}$ situaciones tanto formales como informales y de ocio. En este sentido, la «competencia en comunicación» está inmersa en un entorno digital y de consumo mediático en ambientes de ocio y tiempo libre (Ferrés, 2007).

\section{Fuente de financiación.}

Este trabajo forma parte de una investigación más amplia que tiene la intención de implementar en la ciudadanía andaluza el concepto de «competencia audiovisual»: «La competencia audiovisual de la ciudadanía Andaluza. Estrategias de alfabetización mediática en la sociedad del ocio digital.ALF@MED. Financiado por la Junta de Andalucía dentro del marco de los Proyectos de Excelencia. Código: P10-SEJ5823». 


\section{Referencias bibliográficas.}

Aguaded, I. \& Cruz, R. (2014). O grau de competencia em comunicação audiovisual entre os cidadãos da Andaluzia (Espanha). Comunicação \& Educação, 19(1), 67-72. doi: http://dx.doi.org/10.11606/issn.23169125.v19i1p67-72

Aguaded, J.I., Ferres, J., Cruz, M.R., Pérez, M.A., Sánchez, J. \& Delgado, A. (2011). Informe de investigación El grado de competencia mediática en la ciudadanía andaluza. Huelva: Comunicar ediciones / Universidad de Huelva. Recuperado de http:/ /issuu.com/grupo-comunicar/docs/ competencia-mediatica $?$ mode $=w$ indow\&backgroundColor $=\% 23222222$

\section{Comisión Europea (2009).}

Recomendaciones sobre la alfabetización mediática en el entorno digital para una industria audiovisual y de contenidos más competitiva y una sociedad del conocimiento. Diario oficial de la Unión Europea, Agosto 2009. Recuperado de http://www.mcu.es/cine/ d o c c s / $\mathrm{N}$ o Recomendacion_Comision_Euro pea_sobre_Alfabetizacion_mediatica.pdf

Costa, S., Cuzzocrea, F. \& Nuzzaci, A. (2014). Usos de Internet en contextos educativos informales: implicaciones para la educación formal. Comunicar, XXII (43), 163-171. doi: 10.3916/C43-2014-16

Fernández, C. (2010). Observación y autoobservación de clases. Recuperado de http:/ /es.scribd.com/doc/44891771/Observaciony-auto-observacion-de-clases

Ferrés, J. (2006). La competencia en comunicación audiovisual: propuesta articulada de dimensiones e indicadores. Cuadernos del CAC, 25, 9-17.
Ferrés, J. (2007). La competencia en comunicación audiovisual: dimensiones e indicadores. Comunicar, XV (29), 100-107.

Ferrés, J. \& Piscitelli, A. (2012). La competencia en educación mediática: propuesta articulada de dimensiones e indicadores. Comunicar, XIX (38), 75-82. doi: 10.3916/C38-2012-02-08

García, R., Ramírez, A. \& Rodríguez, M.M. (2014). Educación en alfabetización mediática para una nueva ciudadanía prosumidora. Comunicar, XXII (43), 15-23. doi: 10.3916/C432014-01

Gutiérrez, A. \& Tyner, K. (2012). Educación para los medios, alfabetización mediática y competencia digital. Comunicar, XIX (38), 3139. doi: 10.3916/C38-2012-02-03

«Ley Orgánica 2/2006 de Educación, de 3 de mayo». Boletín Oficial del Estado (núm. 106, de 4 de mayo de 2006), p. 17158-17207.

MEC (2011). Competencia Mediática. Investigación sobre el grado de competencia de la ciudadanía en España. ITE: Madrid.

OECD (2007). Agenda de París de la UNESCO. Doce recomendaciones para la educación relativa a los medios de comunicación. Recuperado de http:// www.oecd.org/dataoecd/59/28/41807824.pdf

Parlamento Europeo (2008). Propuesta de resolución del Parlamento Europeo sobre la alfabetización de los medios en un mundo digital. Recuperado de http://www.oecd.org/ spain/41680537.pdf

Prensky, M. (2001). Digital natives, digital immigrants, part II: do they really think differently?. On the Horizon, 9 (6), 1-6. doi: http://dx.doi.org/10.1108/10748120110424843

Ramírez, A., Renés, P. \& Sánchez, J. (2013). Educación artística y competencia mediática en el currículum de Educación Primaria. Historia y Comunicación Social, 8, 673-686. 
doi: http://dx.doi.org/10.5209/

rev_HICS.2013.v18.43998

Rodríguez, A. (2013). La observación. Recuperado de http://foroalfa.org/articulos/ la-observacion

Rodríguez-Gallego, M.R. (2002). Necesidades fornativas de los alumnos andaluces de magisterio en Nuevas Tecnologías de la Información y la Comunicación. Píxel-Bit. Revista de Medios y Educación, 19, 107-120.

Rodríguez-Gallego, M.R. \& García-Jiménez, F. (2011). Evaluación y transformación de material didáctico en contenido web accesible. Pixel-Bit. Revista de Medios y Educación, 38, 225-238.

Sabirón, F. (2006). Métodos de investigación etnográfica en Ciencias Sociales. Zaragoza: Mira.

Santibáñez, J. (2013). Análisis de la formación de personas mayores en competencia mediática. RELATEC Revista Latinoamericana de Tecnología Educativa, $12(2), 99-113$.

Fecha de recepción: 12-11-2014

Fecha de evaluación: 01-12-2014

Fecha de aceptación: 20-12-2014 